\title{
Acesso ao direito à saúde no cárcere: entre o prescrito e o real
}

RESUMO | Objetivo: Conhecer como ocorre o acesso à saúde das pessoas privadas de liberdade. Métodos: Pesquisa qualitativa, realizada em um presídio no interior de Minas Gerais, com 19 pessoas privadas de liberdade. Os dados foram coletados mediante entrevista aberta orientada por roteiro semiestruturado no período de agosto a dezembro de 2017. Realizou-se Análise de Conteúdo de Bardin. Projeto aprovado no Comitê de Ética e Pesquisa com Seres Humanos. Resultados: Apesar do direito à saúde ser uma prerrogativa constitucional a ser garantida a todo cidadão, inclusive aos privados de liberdade, existem barreiras no cárcere que impedem esse acesso, como: dependência do agente penitenciário por meio de comunicação mediante bilhete, ausência de profissionais de saúde em tempo integral e falta de medicações, necessitando que a família atue como rede de cuidado. Conclusão: Evidencia-se a necessidade de melhor estruturar o acesso à saúde das pessoas privadas de liberdade, a fim de assegurar esse direito.

Palavras-chaves: Direito à Saúde; Acesso aos Serviços de Saúde; Prisioneiros.

ABSTRACT | Objective: To establish how it occurs the access to health care for people deprived of liberty. Methods: Qualitative research, carried out in a prison Minas Gerais's inland, with 19 people deprived of liberty. Data were collected through open interviews guided by semi-structured rotation from August to December 2017. Bardin's Content Analysis was performed. Project approved by the Ethics and Research with Human Beings Committee. Results: Despite being a constitutional prerogative to be guaranteed to all citizens, including people deprived of liberty, there are prision obstacles that prevent this access, such as: dependence on the prison guard through communication by ticket, absence of a health professional full-time and lack of medication, making it necessary for the family to see itself as a care network. Conclusion: The need to structure the access to health care for people deprived of their liberty, in order to ensure their rights.

Keywords: Right to Health; Health Services Accessibility; Prisoners.

RESUMEN | Objetivo: Conocer cómo se dá el acceso a la salud de las personas privó de su libertad. Métodos: Investigación cualitativa, realizada en una prisión del interior de Minas Gerais, con 19 personas privadas de libertad. Los datos fueron coleccionados atraves de una entrevista abierta orientado por un itinerario semi-estructurado. Se realizó el Análisis de Contenido de Bardin. Proyecto aprobado por el Comité de Ética e Investigación con Seres Humanos. Resultados: A pesar de que el derecho a la salud es una prerrogativa constitucional que debe garantizarse a todos los ciudadanos, incluidos los privados de libertad, existen barreras en la prisión que impiden este acceso, tales como: dependencia del guardia penitenciario mediante comunicación vía boleta, ausencia de salud profesionales de salud a tiempo completo y falta de medicación, lo que obliga a la familia a actuar como red asistencial. Conclusión: Se evidencia la necesidad de estructurar mejor el acceso a la salud de las personas privó de su libertad, a fin de garantizar este derecho.

Palabras claves: Derecho a la Salud; Accesibilidad a los Servicios de Salud; Prisioneros.

\section{Beatriz Santana Caçador}

Enfermeira. Professora Adjunta do Departamento de Medicina e Enfermagem da Universidade Federal de Viçosa. Doutora em Enfermagem.

ORCID: 0000-0003-4463-3611

\section{Laylla Veridiana Castória Silva}

Enfermeira. Mestranda em Doenças Infecciosas na Universidade Federal do Espírito Santo. Especialista em Saúde da Família. ORCID: 0000-0002-6488-3485

\section{úlia Torres Amaro}

Médica. Residente de pediatria pelo Hospital Infantil João Paulo II-FHEMIG. ORCID: 0000-0001-5791-7230

\section{Lucas Borges Gomes Ferreira Pinto}

Médico pela Universidade Federal de Viçosa. ORCID: 0000-0002-7936-3343

\section{Thuany Caroline Souza e Silva}

Enfermeira. Residente em Atenção Básica- Saúde da Família no Hospital Odilon Bherens e Secretaria Municipal de Saúde de Belo Horizonte.

ORCID: 0000-0002-9151-0895

\section{Carolina da Silva Caram}

Enfermeira. Professora Adjunta da Escola de Enfermagem da Universidade Federal de Minas Gerais. Doutora em Enfermagem. ORCID: 0000-0001-6219-3301

Recebido em: 29/06/2021 Aprovado em: 16/08/2021
INTRODUÇÃO

população brasileira é marcada por iniquidades e vulnerabilidades sociais, que tornam-se muito claras quando o assunto é saúde, especialmente no sistema prisional. Neste contexto, os privados de liberdade estão expostos a uma série de negligências de direitos humanos e desamparo de garantias fundamentais do direto à saúde ${ }^{1}$.

O direito à saúde está previsto na Constituição Federal de 1988 - artigo 196, como um direito de todos e dever do Estado, e ao se adentrar aos privados de liberdade, está assegurado pela Lei de Execução Penal de 1984 e pela Política Nacional de Atenção Integral à Saúde das Pessoas Privadas de Liberdade no Sistema Prisional (PNAISP) de $2014^{2}$. 
A operacionalização da PNAISP está regulamentada pela Portaria de Consolidação $n^{\circ} 2 / 2017$, a qual tem por referência a população carcerária de determinada unidade prisional para classificar os serviços de saúde bem como seu horário de funcionamento. Ademais, determina a necessidade de integração entre e unidade de saúde prisional e uma unidade básica de saúde do município de modo que profissionais da rede de saúde local do SUS podem atuar no sistema prisional ${ }^{3}$.

A PNAISP visa garantir o direito à saúde e o acesso ao Sistema Único de Saúde (SUS) para todos os indivíduos no sistema prisional, por meio de ações de promoção de saúde e prevenção de doenças, incluindo atendimento, medicamentos e vacinação, por meio da Rede de Atenção à Saúde (RAS) no território ${ }^{2,4}$.

O direito à saúde deve ser assegurado de modo universal, integral e equânime, mediante a compreensão de que cada indivíduo possui sua singularidade, constituindo-se de uma identidade única, que vive sob determinantes sociais e necessita de diferentes formas de cuidado ${ }^{2}$.

Paradoxalmente, o direito à saúde deve ser ofertado pelo Estado à toda população, independentemente de privadas de liberdade ou não, porém, desde quando estão "fora" dos muros do cárcere, devido a marginalização, pobreza e vulnerabilidade, grande parte dessas pessoas não possuem acesso à saúde, e ao se adentrarem no cárcere, esse acesso torna-se ainda mais difícil ${ }^{5}$.

Mediante o exposto, surge a inquietação em relação ao acesso à saúde de uma população privada de liberdade que vivencia o cotidiano em um presídio no interior de Minas Gerais. Sendo assim, questiona-se: Como é o acesso da população privada de liberdade ao direito à saúde? Nesse sentido, o objetivo do estudo foi compreender o acesso de pessoas privadas de liberdade ao direito à saúde.

\section{MÉTODOS}

Estudo qualitativo, realizado em um presídio no interior de Minas Gerais. A pesquisa qualitativa enfoca o mundo dos significados, desejos, aspirações, e valores, o que corresponde a um espaço mais profundo das relações dos processos e dos fenômenos ${ }^{6}$.

Participaram da pesquisa 19 pessoas privadas de liberdade. Os critérios de inclusão foram: maiores de 18 anos sob custódia do Estado em caráter provisório ou sentenciados para cumprimento de pena privativa de liberdade ou medida de segurança. Os critérios de exclusão foram: estar em regime semiaberto, em prisão temporária, por débito alimentar e menores de idade. Foi convidado um participante de cada cela, geralmente àquele com maior tempo de vivência no cárcere.

A coleta de dados ocorreu durante os meses de agosto a dezembro de 2017. Utilizou-se roteiro de entrevista aberta orientada por semiestruturado. Os depoimentos foram gravados e transcritos na íntegra, garantindo a fidedignidade dos dados. As entrevistas apresentaram duração média de 40 minutos a 1 hora e meia. Os agentes penitenciários aguardaram o término das entrevistas do lado de fora da sala, garantindo maior privacidade dos participantes. A fim de garantir sigilo as entrevistas foram identificadas de E1 a E19.

Os dados foram tratados mediante técnica de análise de conteúdo de Bardin7. Realizou-se a pré-análise, com transcrição das entrevistas na íntegra, leitura flutuante e exaustiva do material. Na sequência, procedeu-se a exploração do material, com tratamento descritivo das informações contidas nas falas, transformando-as em dados com significados. Por fim, realizou-se o tratamento dos resultados, inferência e a interpretação, com confronto dos dados à luz da literatura.

Foram respeitados os preceitos éticos da Resolução 466/2012 do Conselho Nacional de Saúde e a Resolução 510/2016 que dispõe sobre as normas aplicáveis a pesquisas em Ciências Humanas e Sociais. A pesquisa foi aprovado pelo Comitê de Ética em Pesquisa com Seres Humanos da Universidade Federal de Viçosa (CEPH-UFV Parecer 2.164.274) e da Secretaria de Segurança Pública do Esta- do de Minas Gerais. Os participantes assinaram o Termo de Consentimento Livre e Esclarecido após serem informados sobre a garantia de anonimato, privacidade e utilização dos resultados somente para fins científicos.

\section{RESULTADOS}

Mediante análise dos depoimentos dos privados de liberdade que participaram deste estudo, evidencia-se que o acesso à saúde no cárcere encontra-se muito distante da perspectiva da universalidade, equidade e integralidade inscritos no SUS.

A forma que os detentos utilizam para manifestarem sua necessidade de saúde e requererem atendimento ocorre por meio de bilhetes entregues aos agentes penitenciários. A estes, fica a incumbência de encaminhar os bilhetes ao setor da saúde para que os profissionais da área realizem o manejo da demanda, conforme evidenciado pelos depoimentos a seguir.
Manda um bilhete pro medico se ele não tiver muito ocupado ele vem no mesmo dia ... se não você tem que esperar. (E12)
Escreve um bilhete pro médico, aí esse bilhete... dá ele pro mé- dico... e o médico manda tirar a gente. (E19) Mando bilhete! (E5)

Ocorre, dessa forma, uma centralidade na figura do agente penitenciário como mediador entre a necessidade de saúde expressa pelo detento e o atendimento por parte dos profissionais de saúde. Significa que a relação estabelecida com o agente penitenciário influencia no encaminhamento - ou não- à demanda manifesta pelo privado de liberdade.

Assim, alguns participantes relatam acesso ao serviço de saúde mediante elo com o agente penitenciário. Mas, também, há relatos de detentos que relatam chutar a grade da cela para que sua necessidade de saúde seja percebida, conforme evidenciado abaixo. 
Olha, eu chamo o agente ne, toda vez que eu precisei, que eu tive problema, me levaram no médi$\mathrm{co}$, me atenderam da forma que deve ser. (E8)

Particularmente toda vez que eu preciso dele, eu mando bilhete, ele me atende. (E11)

Se a pessoa tiver assim muito ruim né, a gente tem que chutar a grade... Primeiro nós chama né? Ao demorar ai vira aquela bagunça né? (E9)

Já vi passando mal dentro de cela pedindo atendimento e não tinha. (E10)

Eu já pedi atendimento, demorava a tirar, a gente até melhorava antes de tirar, até melhorava. (E17)

Com os agente é mais favor mesmo, pedir as coisas, buscar um remédio, mandar bilhete. (E7)

A perspectiva de que o acesso à saúde é um favor ofertado evidencia que os privados de liberdade não reconhecem à saúde como direito. Pelos depoimentos, percebe-se que a demora no acesso à saúde ocorre em decorrência da ausência de profissionais de saúde em tempo integral, bem como da superlotação do presídio. Por isso, há necessidade de prioridade à atendimentos graves, nem sempre sendo possível atender à todos que precisam.

Quem passa mal de madrugada, não tem como, não tem médico atendendo na hora. (E7)

Muita gente pra um médico sozinho atender, entendeu? Pra uma enfermeira sozinha atender. (E2) Demora tirar da cela, fica passando mal um bom tempo. (E6)

Às vezes o atendimento demora. Aconteceu de ter gente mandando bilhete mais de dia e não resolve. (E12)

Passar mal na cadeia é a pior coisa que tem. (E14)

Além da demora em receber atendimento, a maioria dos entrevistados relatam dificuldade de acesso à medicação a qual pode ser considerada como mais uma barreira de acesso aos cuidados em saúde.

Muitas vezes está faltando medicamento, não tem o medicamento para o preso. (E4)

E eles falam pra gente que não tem medicamento, e aí?! Entendeu?! Ele quer que a família traz e tal... mas nem jeito tem de ligar pra família da gente pra pedir pra trazer. Mas a maioria dos medicamentos aqui não tem. (E19)

Percebe-se que a família age como uma importante rede de cuidados, por suprir a ausência do Estado, sobretudo, ao que tange a garantia de acesso às medicações. Entretanto, nem todos os familiares possuem condições materiais para adquirirem medicações, de forma que o acesso aos medicamentos ocorre conforme condições financeiras, o que fere a perspectiva de saúde como direito para todos.

Sempre pedia xarope não tinha, anti-inflamatório, omeprazol também não tem, ai tem que trazer de casa. Peço minha mãe pra trazer, ela traz aí. (E6)

Demora bastante, costuma que nem consegue aqui, às vezes tem que mandar vim de casa pra gente, às vezes a família não tem condição, ai é difícil. (E11)

Quando não tem eles ligam pra família e a família trás. Às vezes a família traz e aí acaba, até eles ligarem pra família, até eles trazerem de novo, acho que se tivesse aqui seria melhor. (E8)

Aqui não tem negócio de saúde, entendeu?! Se o cara quiser ele tem que mandar família trazer o medicamento, se ele não tiver família, ele fica aí jogado aí. (E19)

\section{DISCUSSÃo}

A Constituição Federal Brasileira de 1988 representa importante marco do processo de redemocratização do país e prevê a saúde como condição de cidadania à todo cidadão. Promover saúde extrapola a oferta de práticas de prevenção à agravos e doenças, pois contempla, também, a oferta de ambientes saudáveis, a busca pela qualidade de vida e a proteção de riscos de adoecimento ${ }^{8}$.

Estar privado de liberdade não significa destituir o sujeito de sua dignidade e do acesso aos direitos e garantias constitucionais, como o acesso à saúde. Dessa forma, não é uma opção do Estado naturalizar a negligência dos direitos dessa população ${ }^{8}$.

Sabe-se que, mesmo fora do cárcere, são muitos os desafios para concretizar a garantia de acesso ao direito à saúde no âmbito do SUS. Ainda que em suas bases legais e jurídicas, o SUS seja universal, na prática ele vive de cotas ${ }^{9}$. Assim, existem barreiras de acesso à saúde não apenas no sistema prisional, mas no conjunto do sistema de saúde brasileiro. Há que se ressaltar, porém, que o ambiente prisional potencializa as barreiras existentes, além de propiciar outras condições que agravam as lacunas já existentes.

Neste aspecto, importa trazer para a reflexão a perspectiva de Caputo10 o qual afirma que a privação de liberdade gera, por natureza, deterioração do estado de saúde, configurando-se como uma fábrica de doenças. A privação de liberdade produz efeitos deletérios sobre os corpos tais como distúrbios digestivos e de sono, doenças de pele e nos dentes, depressão, perda auditiva e de visão, dentre outros. Além disso, as precárias condições sanitárias e a superlotação promovem a disseminação de doenças infectocontagiosas.

Também, o cotidiano no cárcere é caracterizado por violências psicológicas e morais, que produzem efeitos devastadores na saúde desta população. A submissão psicológica imposta nesse ambiente age como uma forma de punição, substituindo o castigo físico. Assim, a antiga figura do carrasco, hoje, é personificada pelo agente penitenciário, cujo papel de 
agenciador da reeducação social estabelece importantes relações de poder ${ }^{11}$.

Cabe situar o contexto da família dos privados de liberdade, muitas vezes, marcado por pertença à classe social menos favorecida, que vivencia vulnerabilidades no cotidiano e acesso restrito às políticas assistenciais. Assim, o contexto de vida é caracterizado por pobreza e baixo acesso à saúde e educação ${ }^{12}$.

Em contraponto, mesmo com o contexto de vida caracterizado por pobreza e baixo acesso à saúde e educação, a família revela-se como suporte, capaz de ofertar apoio emocional, econômico e social aos privados de liberdade. Além disso, age como fonte de apoio necessário para encontrar possíveis alternativas e ultrapassar importantes obstáculos, como falta de medicamentos, itens de higiene pessoal, alimentos e contato social exterior ${ }^{13}$.

A dificuldade de acesso à medicamentos fere um dos componentes da PNAISP, em que a assistência farmacêutica deve estar presente em todos os estabelecimentos prisionais, vinculada à rede de serviços de saúde para fornecimento e dispensação de medicamentos, mediante autorização farmacêutica² .
Também, a fim de viabilizar o acesso das pessoas privadas de liberdade ao direito à saúde, a PNAISP determina que cada unidade prisional disponha da atuação de uma equipe multiprofissional composta por médico, enfermeiro, dentista, técnico de enfermagem e técnico de higiene bucal, para atuarem como ponto de atenção da rede de serviços de saúde².

Porém, atualmente, há escassez de profissionais aptos e que desejam trabaIhar com essa população, devido ao conceito cultural de medo e composto por discriminação, e alguns profissionais que atuam nesses locais se deixam levar pela hostilidade e frieza durante o acompanhamento de saúde o que acaba por contribuir com a precariedade do cuidado ${ }^{14}$.

Assim, na dimensão prescrita existem políticas públicas que visam assegurar aos tutelados pelo Estado acesso à saúde, por meio de medicamentos, atendimentos de saúde com profissionais qualificados e em quantitativo ideal, vacinação, realização de exames, dentre outros. Entretanto, percebe-se que na dimensão real deste cotidiano, tais políticas são minimamente efetivadas e produzem resultados incapazes de garantir esse direito fundamental.
CONCLUSÃO

É fundamental compreender como ocorre o acesso à saúde das pessoas privadas de liberdade para que seja possível identificar as lacunas, barreiras e fragilidades que impedem que lhes seja garantido o direito à saúde.

A pesquisa evidenciou que o acesso ao direito à saúde no cárcere, quando ocorre, é atravessado por muitas barreiras tais como. a ausência de profissionais de saúde em tempo integral, a superlotação das celas, a dependência do agente penitenciário para conduzir às demandas, bem como a falta de medicações, auxiliam para que esse acesso se torne meramente uma expectativa de direito e não um direito de fato. A família constitui-se como importante rede de cuidado, porém, nem todas possuem condições financeiras para suprir às lacunas negligenciadas pelo Estado.

Dessa forma, nota-se que é necessário ampliar o horizonte de compreensão acerca da realidade de saúde no contexto do cárcere, sobretudo, a partir da perspectiva das pessoas privadas de liberdade, para que seja possível intervir nesta realidade de forma coerente e capaz de transformá-la.

\section{Referências}

1. Kölling GJ; Silva MBB; Sá MCDNP. O Direito à Saúde no Sistema Prisional. Revista Tempus - Actas de Saúde Coletiva, Brasília, p. 281-297, 2013. https:// doi.org/10.18569/tempus.v7i1.1304

2. Barbosa ML, Medeiros SG, Chiavone FBT, Atanásio LLM, Costa GMC, Santos VEP. Ações de enfermagem no sistema penitenciário. Escola Anna Nery 23(3) 2019. Doi: 10.1590/2177-9465-EAN-2019-0098

3. Simas L; Sánchez A; Ventura M; Diuana V; Larouza B. Análise crítica do modelo de atenção à saúde das pessoas privadas de liberdade no Brasil. Cad. Ibero-amer. Dir. Sanit., Brasília, 10(1): jan./mar., 2021

4. Brasil. Ministério da Saúde (MS). Política Nacional de Atenção Integral à Saúde das Pessoas Privadas de Liberdade no Sistema Prisional. Brasília: MS Ministério da Justiça; 2014. Disponível em: https://bvsms.saude.gov.br/bvs/ saudelegis/gm/2014/pri0001_02_01_2014.html

5. Graça BC, Mariano MM, Gusmão MAJX, Cabral JF, Nascimento VF, Gleriano JS et al. Dificuldades das mulheres privadas de liberdade no acesso aos serviços de saúde. Rev Bras Promoç Saúde, Fortaleza, 31(2): 1-9, abr./jun., 2018. doi: https://doi.org/10.5020/18061230.2018.7374

6. Minayo MCS. 0 desafio do conhecimento: pesquisa qualitativa em saúde. $8^{a}$ ed. São Paulo: Hucitec; 2004.

7. Bardin L. Análise de conteúdo. Lisboa: Edições 70; 2009.

8. Tavares NLF, Garrido RG, Santoro AER. Política de saúde no cárcere fluminense: impactos da pandemia de COVID-19. Revista Estudos Institucionais, v. 6, n.
1, p. 277-300, jan./abr. 2020. doi: 10.21783/rei.v6i1.480

9. Viegas SMF, Penna CMM. O SUS é universal, mas vivemos de cotas. Ciênc. saúde coletiva 18 (1). Jan 2013. https://doi.org/10.1590/S141381232013000100019

10. Caputo G. A pena corporal do cárcere e o direito à saúde: entre a normativa penitenciária europeia e italiana. Revista de Estudos Constitucionais, Hermenêutica e Teoria do Direito (RECHTD)11(2):184-210, maio-agosto, 2019 Unisinos -doi: 10.4013/rechtd.2019.112.04

11. Lourenço LC. Na frente das grades: uma pesquisa com agentes penitenciários da região metropolitana de Belo Horizonte. EDUFBA, 2012, pp. 97-119. ISBN 978- 85-232-1735-8.

12. Lermen HS, Gil BL, Cúnico SD, Jesus LO. Saúde no cárcere: análise das políticas sociais de saúde voltadas à população prisional brasileira. Physis Revista de Saúde Coletiva, Rio de Janeiro, 25 [ 3 ]: 905-924, 2015. https://doi. org/10.1590/S0103-73312015000300012

13. Lourenço LC. Na frente das grades: uma pesquisa com agentes penitenciários da região metropolitana de Belo Horizonte. EDUFBA, 2012, pp. 97-119. ISBN 978- 85-232-1735-8.

14. Carvalho LES, Sousa PCP, Veloso MV, Luz VLES, Feitosa VC. Percepção de detentos sobre a assistência à saúde em um presídio Estadual. R. Interd. v. 9 , n. 4, p. 79-88, out. nov. dez. 2016. Disponível em: https://revistainterdisciplinar. uninovafapi.edu.br/index.php/revinter/article/view/660 